\title{
The 12 Apps of Christmas: an innovative and effective online student and educator support
}

Frances Boylan

Dublin Institute of Technology

\begin{abstract}
The 12 Apps of Christmas course is a free open online course that has run at the Dublin Institute of Technology, Dublin, Ireland, in both 2014 and 2015. The 2014 version of this course was aimed specifically at instructors and went on to win the Mobile Learning Division of the International E-Learning Award (iELA) and come joint third-place at the eLearning Excellence Awards run as part of the 14th European Conference on eLearning. The 2015 iteration was aimed primarily at students of all ages undertaking further education, third-level education and/or postgraduate study, but also included additional supporting information for educators. This case study sets out our experiences of designing and delivering the 2015 iteration of this innovative and effective student and educator support.
\end{abstract}

\section{Introduction}

Mobile learning has been defined by the Mobile Learning Network (http://www.molenet.org.uk/) as "the exploitation of ubiquitous handheld technologies, together with wireless and mobile phone networks, to facilitate, support, enhance and extend the reach of teaching and learning." This definition certainly implies very strongly the potential that mobile technologies, and the mobile learning approach, hold for teaching and learning. However, as Chen and deNoyelles (2013) discovered when they undertook a study exploring student mobile learning practices at their university, there is a gap between the number of students who own mobile devices and those who use them for academic purposes, and those who do use them for academic purposes do so mostly outside the classroom, with limited guidance from their educators. Dahlstrom and Bichsel (2014) disagree slightly with this, as they found that "many students use smartphones or tablets for academic purposes", but agree that "in-class use is still uncommon", adding that "students are more likely to apply mobile devices to academics when instructors encourage their use in class" (Dahlstrom and Bichsel, 2014). Even though students and educators alike use mobile devices regularly, Chen and deNoyelles (2013) concluded their study by suggesting that both groups need technical, logistical and pedagogical support in adopting mobile learning, if its effectiveness as an approach to teaching and learning is to improve. With regard to student usage, Luckin (2015) concurs with this sentiment, noting that "although students arrive at university comfortable with technology, it doesn't mean they know how to use it effectively for learning purposes".

Since 2013, staff of the Learning, Teaching and Technology Centre (LTTC) ${ }^{1}$ at the Dublin Institute of Technology (DIT), Dublin, Ireland, have been supporting educators in one way or another as they explore different mobile technologies and strive to integrate them into their

\footnotetext{
${ }^{1}$ www.dit.ie/lttc
} 
teaching, learning and assessment practices. In December 2014, and again in December $2015^{2}$, they ran a short, free and open online course called The 12 Apps of Christmas ${ }^{3}$. The course was advertised both nationally and internationally in an effort to help interested educators and students alike to expand their personal learning networks and to expose them to as many ideas as possible.

Material was offered to the participants in daily bite-sized chunks, to help them to fit it into their busy schedules. So, 'twelve apps, over twelve days, for twelve minutes a day' was how the course was advertised. This case study begins by explaining the challenges faced and the decisions made in designing the course and delivering it, and then uses the participants' feedback to evaluate it. The study concludes with some final thoughts about measuring the impact of this free online open course.

\section{Course Design and Delivery}

The 12 Apps of Christmas course 2015 ran each weekday for twelve consecutive weekdays from December 1st. A free website builder called Zoho Sites was used to build it (accessible now at: http://www.dit.ie/the12appsofchristmasarchive/) and it was licensed under the Creative Commons License CC BY-NC-SA 2.0. A hybrid app, called '12AppsDIT', was built also and made available for free download from both Google Play and the iOS App Store. Twitter was used as the main channel of communication during the course, via the dedicated hashtag \#12appsDIT, but a comments feature was enabled on the website also for those who preferred to engage in that way.

Following an intensive social media advertising campaign and publicity via national and international learning and teaching networks, 1,967 participants signed up to follow the course from twenty-five different countries. Whilst the course was aimed primarily at students and their educators, the registration sheet shows that just over $40 \%$ of the participants were students, while $59 \%$ noted that they were educators. The remaining $11 \%$ was made up of a mix of instructional designers, educational technologists, librarians, assistive technology advisers and parents.

Over the duration of the course, the participants were introduced to twelve different mobile apps, including OneNote, Office Lens, Trello, Pocket, IF \& DO, MindMeister, RefMe, StudyBlue, Cogi, Maths apps, Flipboard, and PicCollage. As so many apps useful for personalising learning are available, it was very difficult to select just twelve to showcase. The course team started by using personal experience of mobile apps to choose those worth sharing; colleagues recommended others; finally, an extensive online search of relevant blogs and newsletters to see what educational technologists, educators and students worldwide were recommending added a few more. Various alternatives to the selected daily apps were listed each day too, which provided participants with additional choice. In an effort to be as inclusive as possible, a conscious decision was made to showcase only apps available for both Android and iOS

\footnotetext{
2 The 2015 iteration was run in collaboration with DIT Assistive Technology Officer Trevor Boland

${ }^{3}$ This course was based on a similar programme devised by Chris Rowell of Regent's University in London
} 
devices. If the daily app was also available in the Windows apps store, or if a showcased app was available via a browser, then the team highlighted these details.

It was difficult to know: how much content to include without overwhelming the participants; how to make it relevant to them; how to keep them motivated for twelve whole days. As we had done during the development of the first, 2014, version of the course, we turned yet again to the TPACK framework (Technological, Pedagogical and Content Knowledge). In order to integrate technology effectively, the framework proposes that there must be an understanding of the relationship between technology, pedagogy and content (See www.tpack.org). Directed by this framework, the team made a number of design decisions:

1. To drip-feed content daily: each morning, a new page to be released on the website and on our own app, and participants each to receive a short email, alerting them to the fact that the daily app was now available for review.

2. To deliver via the daily pages a bite-sized piece of information about that day's mobile app and to design those pages to take no more than twelve minutes a day of each participant's time to read the information.

3. To provide links to additional information and also short demo videos for those who might want to delve a little deeper.

4. To provide a short additional optional task, so that participants might use the app in a purposeful and structured way and in, some cases, share with the other course participants, via Twitter, what they had created.

5. In order to keep the participants motivated and engaged, to gamify a number of the optional tasks and to raffle prizes.

The 12 Apps of Christmas course was designed in the context of social constructivist learning theory and, where possible, opportunities were embedded into the course to facilitate communication in the form of collaboration, resource-sharing and discussion. The daily email reached out to the participants to make them feel included and encouraged them to engage on Twitter. For those who did not have, nor wanted to have, a Twitter account, the Twitter feed was embedded into the website, so that they could follow the discussions there and not miss out. Each time there was a competition, entry tweets were archived, using Storify, and a link to the 'story' was disseminated. As mentioned previously, comments were enabled on the website too, so that participants could be involved there. An evident lack of student engagement with Twitter however, apart from when a competition was being run, might be explained by the fact that they were quite busy at that time of the year; or, perhaps, as some of the student Twitter accounts appeared to have been only recently set up, with few tweets other than those with \#12appsDIT, Twitter might not have been an application they were either interested in or familiar with. Should students be invited to participate in another iteration of this course, such alternative methods of communication and engagement as Facebook or Snapchat would have to be explored.

However, of the 102 educators, librarians and learning technologists etc. who supplied feedback on the course, $36 \%$ said that they tweeted to \#12appsDIT during the course and $43 \%$ said that, whether they did or did not post comments or tweets themselves, they learned from reading what others had posted and/or tweeted. 
To quote Olsen (2011), "we need to develop learners who are skilled at personalising their learning, as the changing nature of knowledge means this is a fundamental skill for today's workforce". A personalised approach to learning is taken when students and their educators work together to tailor pedagogy, curriculum and the learning environment to cater for each students' learning needs, and the benefits to this approach include increased engagement, retention and success. The 12 Apps of Christmas 2015 set out to demonstrate to students how they themselves could harness the power of mobile apps to help them begin to personalise their learning. It also attempted to highlight some small changes that educators could make to their day-to-day teaching and learning practices to begin to create a learning environment that would encourage their students to harness mobile apps in this way. To this end, included on the website was a page written specifically for students, explaining that, when they learn in a way that suits them, they are much more likely to understand and retain new knowledge, and reminding them that, regardless of our preferred learning styles, we all benefit from learning with others, sharing and creating knowledge. That page also set out the following four steps that they would need to follow to start the process of personalising their learning:

1. Discover how you learn best, by taking a short inventory that tells you whether you are a visual, auditory, read/write or kinaesthetic learner (VARK) and read up on what the result means for you. A link to an online inventory was provided (http://bit.ly/1retoy2; Juskeviciene and Kurilovas, 2014).

2. Take the time to categorise this information under the headings:

a. How do you like to access and process information?

b. How do you like to engage with that information?

c. How do you prefer to express your knowledge and understanding of that information?

3. Decide what your immediate and long-term learning goals are, so as to start to take control of your learning.

4. Choose tools and technologies that will help you to achieve your learning goals while playing to the strengths of your preferred learning style. This is where The 12 Apps of Christmas course comes in.

Furthermore, a page for educators was included on the site, which gave examples of small changes that they could make to their teaching and learning practices to help create a learning environment within which their students could harness the opportunities mobile apps present for personalising learning.

Each day, the app of the day was evaluated for the participants under each of the VARK styles, and within each of those sections the featured app was discussed in terms of how it could support those students to access information, engage with it and express their understanding of it. This information for the auditory learners was provided daily as an audio clip. Ways in which that app could facilitate communication and collaboration were also shared.

As part of the 12 Apps course, Professor John Traxler, Professor of Mobile Learning at the University of Wolverhampton, kindly ran a webinar entitled 'Spoilt for Choice' for all of the participants, during which he shared his insights on mobile technology and its possibilities for 
education. A recording of that webinar has been made available, with Professor Traxler's permission, as a resource on the course website.

\section{Evaluating the Course}

With the participants' permission, a wide range of anonymous data was collected about all aspects of The 12 Apps of Christmas course. This data was collected via: open and closed questions on the registration form; the comments on the website; website analytics; analytics from our bespoke app; tweets sent that included '\#12appsDIT'; two different post-course feedback surveys, one of which was sent to those who had identified themselves as students, and the other to everyone else who had registered to participate.

For the month of December 2015, the month during which the course ran, website analytics show that there was a total of 39,178 page views. The first two days of the course were the busiest, with over 4,500 page views each day. The statistics fluctuated for the remaining ten days, from the lowest, 2,149 views, to a high of 3,778. The site has continued to be accessed into 2016, with January and February having proved to be the busiest months, showing a combined total of 5,342 page views. So far in 2016, there has been a total of 12,876 page views, so the site is living on as a useful resource for all.

Feedback surveys were sent out to all participants in early March 2016. Because the course had run at a very busy time, with many students undertaking exams both before and after Christmas at the end of semester one, we chose to delay sending out the two post-course feedback surveys. We wanted to give the students a chance to have started using some of the apps for personalising their learning, and the educators an opportunity to think about how they might encourage their students to start using mobile apps in this way and possibly even integrate some of the apps into their teaching and assessment practices. As a result, however, the response rate was disappointingly low, with responses from just 102 educators and only 38 students. Nevertheless, the feedback given was quite insightful. $41 \%(n=42)$ of the educators who provided feedback said that they followed the course for the whole twelve days, with a further $50 \%(n=51)$ saying that they followed it for some of the days. The main reason given for not following the course every day was workload. $40 \%(n=41)$ noted that they had returned to the different pages a number of times during the course and $30 \%(n=30)$ that they had returned to the site since the course had ended. $41 \%(n=42)$ had gone on to recommend the site as a resource to a colleague, friend or student since the course had ended.

Interestingly, $28 \%(n=29)$ of the educators said that they had already gone on, as a direct result of the course, to make changes to their teaching and/or assessment practices in the three months since the course had run, whilst a further $42 \%(n=43)$ said that, though they hadn't made any changes yet, they planned on doing so in the next academic year. It was also interesting to see that the course had motivated them to start exploring alternative apps; as one participant said, the course "encouraged me to try out similar apps to those presented during the 12 days and compare them. It helped me select which ones were relevant and practical for me and also show a wider range of options to students/faculty'. The participants were also positive about the course as a whole and what it had set out to achieve; one said, "the info on how the apps supported different learning styles was useful. It added an extra dimension for me. 
If asked by a student why they might want to use an App I would feel I could respond with more confidence." Poor wifi was mentioned in $17 \%(n=18)$ of the responses given concerning barriers to mobile learning, the integration of mobile apps for learning and the personalisation of learning; a lack of awareness, confidence, time and training were also emphasised.

Of the thirty-eight students who responded to the question in their survey which asked if the course had been worthwhile, $89.5 \%$ said that it had. 70\% said that, having followed The 12 Apps of Christmas course, they would now consider using mobile apps for educational purposes, and $59 \%$ had gone on to make some changes to how they approached their study, having read about personalised learning during the course. Like their educators, time constraints were mentioned as one of the main reasons for not following all of the course.

\section{Final Thoughts}

Given the free, open and optional nature of this kind of short course that is run online via social media, it is quite difficult to measure, in any accurate way, either the initial or continuing impact it might have had on its participants and beyond. The responses in the feedback surveys did provide some valuable insights, but, as the response rate was very low in this instance, trustworthy inferences as to the overall impact of the course cannot be made.

However, some of the participants made contact to share with us how they were using the course and this gave us a glimpse of the kind of extended reach it was having, which, as it turned out, was well beyond our expectations. To give some examples:

- A teacher in Spain got all of his students to sign up and follow The 12 Apps of Christmas course as an integral part of their own course - effectively, our course was being used as a live, open educational resource (OER) that supplemented their own content, and that was fantastic;

- A college in the United Kingdom also contacted us to say that it was running a whole mobile learning event around The 12 Apps of Christmas course - a committee had been established, which set up around the college three decorated booths (with, in each, laptops which displayed that day's app page) and its members actively encouraged the students to take part in the course and engage with the content;

- Four months after the course finished, a language lecturer in the USA tweeted to \#12appsDIT to share their institution's 'Apps at a Glance' project on mobile apps for language learning and attributed the project idea to the structure and content of The 12 apps of Christmas course.

These examples, along with the survey feedback, do show that the course was of value. It certainly raised awareness amongst educators, students, educational technologists, librarians and parents alike of the potential mobile apps hold for personalising learning; in addition, not only did it offer technical, logistical and pedagogical support to its own participants, it also inspired others to do the same elsewhere.

Another iteration of this course is planned for December 2016; it will be aimed at educators and educational technologies specifically, rather than at students. Nevertheless, the apps that will be 
showcased may well be of interest to students and other groups, too. A link to the 2016 course will be made available on http://www. dit.ie/the12appsofchristmasarchive/ in November 2016. Lessons learned regarding methods of communication and the timing of the feedback survey will be considered during the planning stages.

\section{Acknowledgement}

The author would like to acknowledge the work of Trevor Boland, an Assistive Technology Officer at DIT, on The 12 Apps of Christmas course 2015.

\section{Reference list}

Chen, B. and deNoyelles A. (2013) 'Exploring Students' Mobile Learning Practices in Higher Education.' Available at: http://bit.ly/2aVviCC (Accessed: 10 August 2016).

Dahlstrom, E. and Bichsel, J. (2014) ECAR Study of Undergraduate Students, 2014, 17. Available at: https://net.educause.edu/ir/library/pdf/ss14/ERS1406.pdf (Accessed: 10 August 2016).

Juskeviciene, A. and Kurilovas, E. (2014) 'On Recommending Web 2.0 Tools to Personalise Learning.' Informatics in Education, 13(1), 17-31.

Luckin, R. (2015) Jisc-sponsored supplement from Times Higher Education, 29 October 2015. Available at:

http://digital.timeshighereducation.co.uk/JISCSUPPLEMENT2015/html5/index.html?page=1 (Accessed: 25 July 2016).

Olsen, $R$ and ideasLAB (2011) 'Understanding Pedagogies for Contemporary Teaching \& Learning: an ideasLAB White Paper.' Available at: http://bit.ly/1WN2pdu (Accessed: 10 August 2016). 